\section{Pixelating the populace}

\author{
Lewis M. Branscomb
}

Being Digital. By Nicholas Negroponte. Knopf/Hodder and Stoughton: 1995. Pp. 243. \$23, £12.99.

READERS of Wired magazine are familiar with Nicholas Negroponte's columns, from which the best parts of this book are drawn. Leonardo da Vinci recognized that reality is most effectively described through the eye. Negroponte and his colleagues at the Media Lab at the Massachusetts Institute of Technology would agree, but would include the mind's eye (virtual reality) too. In their view, information should be experienced through all the senses and through the imagination.

Current debate about 'information infrastructure' concerns the providers of content (publishers and radio, television and movie producers) and conduit (telephone, cable, satellite and computernetwork servicers). Negroponte sees conduit and content as inextricably linked, preferring to distinguish between the merits of digital versus analog information and services.

In the digital world, information is understandable to computers, which can quickly transform it for use by humans, trapped as we are in our hopelessly analog condition. But computers are still novelties to most people. The overwhelming majority of every country's information infrastructure today is comprised of the real, analog world of telephones and television. Only a third of homes in the United States have a computer, whereas about 93 per cent have a telephone and 98 per cent have a television set. Neither the telephone nor the television is now digital.

Analog information services are doomed to obsolescence in Negroponte's world. To sharpen the distinction between analog and digital information, he identifies analog information with the physical media through which it is carried, transformed and embodied. He calls physical media "atoms". Digital information is encoded in units of information called "bits". Negroponte celebrates the abstract nature of bits, and of bits about bits (the message headers that tell packetswitched networks what to do with the content). It is not enough, however, to be digital: we must embrace the multisensory world in which pixels (comprised of bits) are the elements of images. Being Pixelated as a title would have captured this thought and Negroponte's somewhat flippant but readable discourse.

Being Digital is written for the lay reader, not for the scientist or sophisticated computer user. The book's jacket commends it to those "lost on the information highway", a misleading metaphor which Negroponte, to his credit, rarely uses. It claims, astonishingly, that this is the "first book to explore the impact of digital technology on the world", but more scholarly books on the subject have appeared by the hundreds since the late 1970s. The text is divided into three sections. The first part is intended to help naive readers understand the other parts, although in fact it will probably confuse most lay readers and surely irritate the technically trained. Much of it is written in 'bitspeak' - the text equivalent of soundbites. Some statements remind one of Marshall McLuhan: "flight simulation. .. is more realistic than flying a real plane".

The most interesting part of the book is found in the second and third sections. Here Negroponte predicts the convergence of information media: television will begin'to look more like a newspaper, offering a broad menu of information from which to choose; our personal computer will make each of us our own publisher, if we let it know enough about our individual needs; and our personal "interface agent" will browse through the huge choice of multimedia information and select just what we want, packaged in the format and media we want.

His model of the right computer design is the English butler. In the "post information age" foreseen in this book, everything is individualized: the audience size is one; being digital means I am unique.

'Multi-media' must be viewed as an integrated sensory experience to be effective. When Russ Neuman showed Media Lab focus groups identical terevision signals with different audio qualities, observers selected those signals with the best sound quality as having a superior picture - which is why Negroponte wears his glasses when he eats.

The least satisfactory part of the book is its view of how law and economics will influence the realization of Negroponte's vision. The author suggests that copyright law will "break down completely before it is corrected" - even John Perry Barlow, a critic of copyright and a regular contributor to Wired, doesn't take such an extreme view. And he worries that readers of an electronic New York Times will bypass it and subscribe directly to their favourite writers through the Internet. The reason this doesn't happen today is that the New York Times knows how to write an employment contract.

Survivors of the publishing industry will transform themselves into trusted information brokers and suppliers of information agent software. As Negroponte points out, the value of information about information can exceed the value of the information itself. Its ultimate value depends on reliability, comprehensibility and suitability for use. People smarter or better informed than ourselves will always be paid to be the trusted editors of good books or the authors of trusted agent software.

Lewis M. Branscomb is at the John F. Kennedy School of Government, Harvard University, 79 J. F. K. Street, Cambridge, Massachusetts 02138, USA.

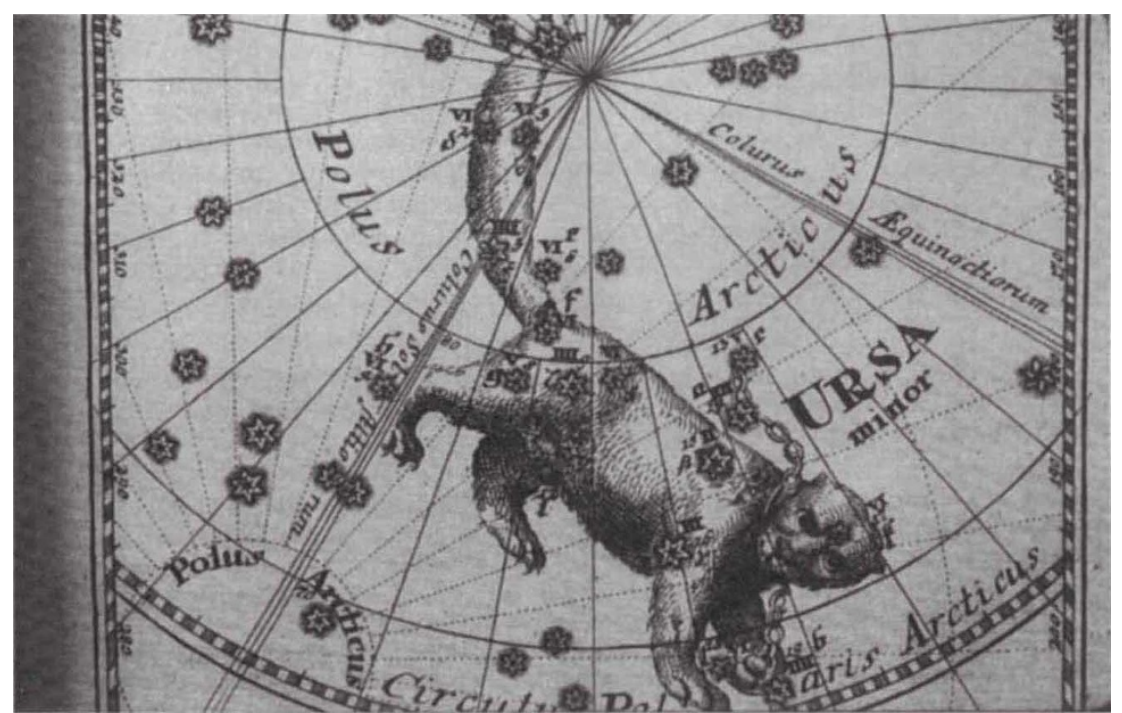

Ursa Minor, from Corbinianus Thomas's Mercurii Philosophici Firmanentum Firmianum (1730). The picture appears in The Cambridge Guide to the Constellations by Michael E. Bakich. Cambridge University Press, $£ 35, \$ 49.95$ (hbk), £14.95, \$19.95 (pbk). 